This is the final peer-reviewed accepted manuscript of:

Giacomo Antonioni, Gabriele Landucci, Amos Necci, Diana Gheorghiu, Valerio Cozzani, Quantitative assessment of risk due to NaTech scenarios caused by floods, Reliability Engineering \& System Safety, Volume 142, 2015, Pages 334-345, ISSN 0951-8320

The final published version is available online at:

https://doi.org/10.1016/j.ress.2015.05.020

Rights / License:

The terms and conditions for the reuse of this version of the manuscript are specified in the publishing policy. For all terms of use and more information see the publisher's website.

This item was downloaded from IRIS Università di Bologna (https://cris.unibo.it/)

When citing, please refer to the published version. 


\title{
Quantitative Assessment of Risk due to NaTech Scenarios caused by Floods
}

\section{Giacomo Antonioni ${ }^{\mathrm{a}}$, Gabriele Landucci ${ }^{\mathrm{b}}$, Amos Necci ${ }^{\mathrm{a}}$, Diana Gheorghiu ${ }^{\mathrm{c}}$, Valerio Cozzani ${ }^{\mathrm{a}^{*}}$}

\author{
Revised Version
}

a) Laboratory of Industrial Safety and Environmental Sustainability - DICAM, Alma Mater Studiorum - Università di Bologna, via Terracini n.28, 40131 Bologna, Italy

b) Dipartimento di Ingegneria Civile e Industriale, Università di Pisa, Largo Lucio Lazzarino 1, 56126 Pisa, Italy

c) Faculty of Environmental Sciences and Engineering, Babeş-Bolyai University, Fântânele Street, no. 30, 400294, Cluj-Napoca, Romania

(*) Author to whom correspondence should be addressed.

tel. (+39)-051-2090240; fax (+39)-051-2090247

e-mail: valerio.cozzani@ unibo.it

Submitted for publication in:

RELIABILITY ENGINEERING \& SYSTEM SAFETY 


\begin{abstract}
Floods may cause severe damages to chemical and process facilities, triggering major accidents (fires, explosions, toxic release). Such cascading events are termed as NaTech scenarios. In the present study, a specific methodology for the implementation of Quantitative Risk Assessment (QRA) of NaTech scenarios triggered by floods was further developed and applied to the assessment of different flood events and equipment categories. Specific vulnerability models allowed estimating the failure probability of both atmospheric and pressurized equipment, and the estimation of NaTech-induced release frequencies. A case-study representative of an industrial installation was discussed, comparing the risk due to conventional internal causes to that deriving from NaTech scenarios and identifying possible specific safety barriers. The case study demonstrated that a significant risk increment may be associated to industrial facilities located in flood-prone areas when flood-triggered NaTech scenarios are considered.
\end{abstract}

\title{
Keywords:
}

NaTech scenarios; major accident hazard; hazardous materials release; quantitative risk assessment; flood; equipment vulnerability models. 


\section{Introduction}

In the chemical and process industry, severe accidents can be triggered by the impact of natural events on process and storage equipment, leading to the loss of containment (LOC) of dangerous substances [1-5]. This type of accidents, defined as "natural-technological" (NaTech) events, occurred several times in the past. Previous works recognized the criticality of NaTech events through the analysis of major accident databases, in particular describing accidents triggered by floods [6], earthquakes [7] and lightning [8]. Several studies addressed the development of dedicated NaTech disaster risk management strategies for urban areas [9] or industrial installations [10-12]. Fendler [13] presented the results of the German Environment Agency project aimed at improving management strategies for flood risks in installations storing hazardous materials. Necci et al. [14] reported a specific study on accidents triggered by lightning taking into account the response of the fire safety barriers. Busini et al. [15] proposed a simplified screening tool to identify which situations require the need of more detailed studies such as Quantitative Risk Assessment (QRA). Salzano et al. [16,17] addressed in detail the response of industrial equipment to seismic events, while Milazzo et al. analyzed the effect of volcanic ash fallout on storage facilities [18]. The potential severity of NaTech accidents impact was discussed by Krausmann and Mushtaq [19], and evidenced by the recent catastrophic events occurred in Japan after the Tōhoku earthquake and consequent tsunami (April 2011) [20].

Therefore, considering NaTech scenarios in the framework of safety reports and of Quantitative Risk Assessment (QRA) of industrial facilities where relevant quantities of hazardous substances are stored or processed is of utmost importance to correctly assess the risk associated to site operation and for robust and effective emergency planning in residential areas near to these industrial sites [11,12,21-23].

Previous studies pointed out that the assessment of the frequency of accident scenarios associated to NaTech events is a critical task in QRA. In fact, equipment-specific fragility models are needed in order to estimate equipment damage probabilities as a consequence of the severity of the natural event. Salzano et al. discussed vulnerability models for atmospheric storage tanks involved in seismic events [16] and developed specific risk based early warning systems for industrial facilities in seismic zones [17]. Cozzani and coworkers showed the application of vulnerability models in the framework of risk assessment taking into account NaTech events triggered by earthquakes [21,22].

Due to the features of a QRA study, that usually requires the assessment of a high number of scenarios, the use of simplified models able to yield a conservative estimation of equipment failure probabilities is required to effectively support the assessment of equipment vulnerability. This was previously discussed by Landucci et al. [24] and Cozzani et al. [25], where the use of equipment vulnerability models was applied to the assessment of domino effect due to internal process causes (e.g., fires, explosions, fragment projection). With respect to NaTech scenarios triggered by floods, recent studies allowed determining specific fragility models for both atmospheric and pressurized equipment, considering different types of geometries and flooding conditions [26-28]. Such models represent an important upgrade of the previous overconservative tools available to assess equipment fragility due to floods (e.g. see the study of Antonioni et al. [21]). However, the effect on quantitative risk assessment deriving from the implementation of these new models was not explored to date.

The present study aimed at exploring the quantitative assessment of risk caused by floods impacting on industrial facilities where relevant quantities of hazardous substances are present. The new equipment vulnerability models now available were implemented in the QRA methodology developed by Antonioni et al. [21], allowing a detailed calculation of risk profiles due to NaTech events triggered by floods. A reference case study was analyzed, based on an actual industrial layout taking into account different flooding conditions, and comparing results with and without flood-triggered NaTech scenarios. The results obtained evidence the high influence of NaTech caused by flood on the overall risk profile of a facility. Furthermore, the new fragility models 
developed allow a more detailed analysis and identification of critical equipment items and of critical flood scenarios.

\section{Methodology}

\subsection{Approach to the introduction of NaTech scenarios in QRA}

The methodology for the introduction of NaTech scenarios in Quantitative Risk Assessment was developed in previous studies [21,22]. Hereby the main elements of the procedure are summarized, according to the scheme reported in Fig.1, and specific elements introduced to consider NaTech scenarios triggered by floods are discussed.

\section{[INSERT FIGURE 1 HERE]}

The starting point of the methodology is the identification of reference flood conditions, thus determining the reference scenarios to be considered in the QRA. Each flood event needs to be characterized in terms of frequency and of severity by a sufficiently simple approach, suitable for the use in a risk assessment framework (step 3 in Fig. 1). The standard parameter for flood frequency evaluation is the return period $\left(t_{r}\right)$ measured in years and given by hydrological studies $[29,30]$. This is usually available from local competent authorities [31-34]. The flooding frequency $f$ can thus be estimated as follows:

$f=1 / t_{r}$

Next, an impact vector, whose elements represent the severity of the flood scenario, needs to be defined for each of the reference scenarios selected. It must be remarked that this step by no way is intended to provide a characterization of the flood hazard at the site, nor to provide data for a detailed analysis of the damage to structures, but only to obtain the input data necessary for the application of simplified equipment damage models. In particular, flood severity can be quantified by two parameters $[3,6,11,21,26,27]$ : water effective depth $\left(h_{w}\right)$ and water speed $\left(v_{w}\right)$. The effective depth should take into account the possible effect of protection measures, such as concrete supports higher than the ground level to which the vessel saddles are fixed.

Simplified hazard ranking criteria based on inventory and physical state of hazardous substances may be used to identify critical equipment items that should be included in the analysis (step 4 in Fig. 1) [21]. The application of equipment vulnerability models is then needed to assess the equipment damage probability (step 5). These models are discussed in the following section. Consequence assessment of the single scenarios triggered by the natural event (step 6) may be carried out by conventional models [35-37], although a limited number of specific final outcomes may arise [6,21].

The final steps of the procedure (steps 7-10), aimed at risk recomposition, may be carried out as for domino effect assessment [25,38] and are briefly outlined in Section 2.3.

\subsection{Equipment vulnerability models}

Data on equipment failure as a consequence of floods are scarce in the literature. Antonioni et al. [21] report a general correlation that allows a rough estimate of the failure probability. More recently, Landucci et al. have developed a simplified approach to evaluate the failure probability of vertical atmospheric tanks for liquid storage [26] and of horizontal atmospheric or pressurized vessels [27]. The approach is based on the evaluation of vessel mechanical integrity under the action of the flood, which results in both a "static" external pressure component, due to the depth of the flooding (namely, $h_{w}$ ), and in a "dynamic" external pressure component, due to the flood water velocity (namely, $v_{w}$ ) and to the associated drag force. In the case of atmospheric vertical vessels it was evidenced that the vessel filling level is the more relevant parameter for the evaluation of the 
equipment integrity and of the failure probability. Thus, a critical filling level $\left(C F L_{v}\right)$ was defined for each equipment item involved in a specified flooding event of given intensity (e.g., having assigned flood water speed and depth), as the liquid level below which the failure for instability is possible. Table 1 reports a simplified correlation for the estimation of $C F L_{v}[26,28]$ and the associated vulnerability model for atmospheric vessels involved in flooding.

\section{[INSERT TABLE 1 HERE]}

The approach was extended in order to obtain the fragility model for horizontal cylindrical vessels, both atmospheric and pressurized. In this case, the possibility of having a rupture following the flood event is related to the resistance of the connection between the vessel framework (e.g., saddle or other support structures) and the ground. As reported in the analysis of specific past accident data [6,39-41], the rupture of the framework may cause the displacement of the vessel, with the consequent rupture of the vessel connections and its potential impact with adjacent units or structures. Hence, the possibility of having a LOC following a flood for these vessels is directly related to the integrity of the framework connection to the ground. The connection should resist to the lift force due to the floating action of the floodwater and, at the same time, to the shear action due to the flood wave drag force. Therefore, also in this case the filling level results a critical parameter for the assessment of the vessel resistance. Flood impact also generates a torque action impacting on the vessel, that is a function of the vessel geometry and flooding velocity $v_{w}$. Hence, in order to estimate the failure probability of a horizontal vessel due to flood impact, two threshold parameters were used as a reference: the critical water velocity, $v_{w, c}$ and the critical filling level for horizontal vessels, $C F L_{h}$. The first represents a threshold condition for velocity over which the drag force generated by flood water is sufficient to cause the failure of the bolt connection for a given floodwater height. Simplified correlations for the estimation of $v_{w, c}$ are reported in Table 2 and were developed in a previous study [27]. The second parameter defined $\left(C F L_{h}\right)$, is the same applied for vertical vessels. The assessment of $C F L_{h}$ and its evaluation through simplified correlations [27] is summarized in Table 2.

\section{[INSERT TABLE 2 HERE]}

\subsection{Implementation of NaTech scenarios triggered by floods in QRA}

\subsubsection{Consequence analysis of credible scenarios}

The main assumptions introduced for the consequence assessment of NaTech scenarios triggered by floods are summarized in the following.

For pressurized vessel, flooding may cause vessel displacement, while vessel rupture due the external pressure or wave impact is not credible due to the high thickness of vessel shell required to resist to the typical design pressures [27]. Vessel displacement is likely to cause the rupture of pipe connections and nozzle flanges. Thus, the release event was selected as the more severe between: (1) the release of the entire content of the vessel considering a full bore rupture of pipe connections; and (2) the release in $10 \mathrm{~min}$ of the entire inventory. Moreover when a dispersion model is applied for the calculation of toxic effects or of flash-fire thresholds, values in the range of 0.1 to $1 \mathrm{~mm}$ should be selected for the roughness length [42]. These values are typical of sea surface [43] and are suitable for dispersions over the water surface in general.

For atmospheric tanks, a flood can affect the integrity of the tank shell due to its limited thickness. Hence, a catastrophic release can be assumed and the resulting liquid pool can be considered unconfined. In fact, flood water level must be higher than a possible catch basin wall in order to affect the tank. 
On the basis of the above defined release scenarios and source terms, Event Tree Analysis (ETA) was applied to determine the possible final outcomes according to conventional procedures as those of the "Purple Book" [35-37,44]. Due to the nature of the substances released in the case-study, scenarios due to chemical interactions between the substance released and the flood water [6,39] were not considered in the assessment. Physical effects associated to the final outcomes of the release scenarios were calculated by literature models [35-37].

\subsubsection{Risk recomposition}

Steps 7-10 were carried out following the NaTech risk assessment framework introduced in a previous study [21], based on the methodology developed by Cozzani et al. [25,38,45] for domino effect risk assessment.

After the determination of equipment failure probabilities, the identification of credible combinations of events (step 7) and the evaluation of the resultant frequency (step 8) need to be carried out. The main is assumption is that, given a facility having $n$ target equipment affected by a flooding scenario, the damage of any target is independent from a probabilistic point of view. Thus, the damage probability of a unit during the flooding event (namely $\Psi$ and evaluated according to the methods described in Section 2.2) may be considered independent from the possible contemporary damage of $n-1$ other units. However, more than one unit may be damaged simultaneously during the flooding event. A single accidental scenario induced by flooding may thus be defined as an event involving the contemporary damage of $k$ of $n$ units resulting in $k$ final outcomes, with $k$ comprised between $l$ and $n$. If a numerical index ( $l$ to $n)$ is assigned to each of the $n$ events that may be triggered by flooding, a single overall NaTech scenario may thus be identified as a vector $\left(\mathbf{J}^{k}{ }_{m}=\left[\gamma_{1}, \gamma_{k}\right]\right)$, whose elements $\left(\gamma_{j}(j=1, \ldots, k)\right)$ are the indexes of the $k$ rupture events that take place during the flooding scenario. The probability of a single overall NaTech scenario involving the contemporary damage of $k$ units resulting in $k$ events due to flooding, identified by the vector $\mathbf{J}^{k}$, may then be calculated. The expected frequency of the $m$-th overall flooding scenario involving $k$ simultaneous equipment damages, $f_{f}^{(k, m)}$, may thus be calculated.

In order to limit the number of combinations considered for the risk assessment, a frequency cut-off value was assumed. Combinations of events having frequency of occurrence lower than cut-off value of $10^{-10} 1 / \mathrm{y}$ were excluded from the analysis, since not credible.

The consequences of accident combinations triggered by flooding need then to be assessed (step 9 in Fig. 1). The consequences of a generic $(k, m)$ scenario triggered by flooding may not be assessed directly using conventional models for consequence analysis, that assume single point-source scenarios. The same approach adopted for domino effect escalation scenarios was therefore applied $[25,38,45]$. Finally, step 10 of the methodology (see Fig. 1) consists in the risk recomposition based on the obtained frequency and consequences results and was carried out according well known procedures [35-37,44].

Table 3 summarizes the numerical correlations applied for frequency and vulnerability calculation. Further details on the methodology are reported elsewhere $[21,25,38,45]$.

\section{[INSERT TABLE 3 HERE]}

\subsection{Description of the reference case-study}

\subsubsection{The lay-out of the industrial site}

In order to demonstrate the application of the methodology and to understand the importance of considering flood-induced NaTech scenarios, a QRA of a case-study was carried out. The lay-out of the industrial facility selected for the study is shown in Fig. 2. It should be remarked that in the layout both atmospheric and pressurized tanks are present.

Table 4 reports the features of the vessels considered and the inventories of hazardous substances. Both horizontal and vertical tanks were considered. All the horizontal vessels were assumed to be 
supported on a concrete base $(0.25 \mathrm{~m}$ higher respect to ground level), that may provide a protection from low-depth flooding.

\section{[INSERT FIGURE 2 HERE]}

\section{[INSERT TABLE 4 HERE]}

\subsubsection{Workers and surrounding population}

The industrial facility is organized for continuous operation $24 \mathrm{~h} /$ day. Thus, inside plant area, a constant presence of 100 workers was considered. The workers were considered as evenly distributed in the plant area. A 50\% probability of being present outdoor was considered.

Census data were used as the basis for societal risk calculation. Figure 3 shows the distribution considered for resident population. Daily averages for presence probability of resident population were considered $[44,47]$. The values adopted, including the probability of being indoor or outdoor (and thus partially sheltered from harmful effects), are reported in Table 5.

\section{[INSERT TABLE 5 HERE]}

\subsubsection{Flood reference scenarios}

The flood reference scenarios are summarized in Table 6. The table also reports the frequency associated to the four reference scenarios considered. Flood frequency was derived from the available values of the return time, applying Eq. 1.

\section{[INSERT TABLE 6 HERE]}

As mentioned in Section 2.1, the flood impact vector is characterized by two relevant parameters: water effective depth $\left(h_{w}\right)$ and water speed $\left(v_{w}\right)$. The four reference scenarios were selected in order to consider different types of flood waves. In particular, extremely severe conditions were assumed for the first two reference scenarios (Case 1 and Case 2). In the first case, high depth flooding with limited speed was taken into account. On the contrary, in the second case a "flash-flood", with high speed but with small depth was assumed. Both conditions are associated to low frequency values (see Table 6). The other reference scenarios (Case 3 and Case 4) were associated to lower severity flood conditions, but having a lower return time and, thus, a higher occurrence frequency.

Thus, the reference scenarios defined allowed the impact assessment of several types of flood scenarios, having different damage potential and expected frequency.

\subsubsection{QRA of conventional scenarios}

In order to understand the importance of NaTech scenarios triggered by floods, a QRA of the "conventional" scenarios due to internal failures was first performed, to obtain reference values for individual and societal risk. The expected frequency of top events were defined according to the "purple book" [29]. Table 7 reports the end-point frequencies of each scenario considered for the risk sources analyzed. The consequences of the end-point events listed in the table were assessed by literature models [35-37] on the basis of some of the assumptions discussed in Section 2.3.1. The physical effects calculated were then implemented in the Aripar-GIS software $[48,49]$.

\section{[INSERT TABLE 7 HERE]}

Fig. 4 reports the individual risk calculated for the conventional scenarios considered for the casestudy. The risk contour at the threshold value of $10^{-6} 1 / y$ is within the industrial area, while only lower individual risk levels are present in the residential areas. The risk associated to conventional scenarios is compared in Section 3 with the risk results obtained considering NaTech scenarios and 
summarized in Fig. 5. The F/N curve calculated to express the societal risk for the conventional scenarios is reported in Fig. 6. In terms of Potential Life Loss (PLL), 8.84 fatalities per thousand year are expected. These results will be the baseline values for the comparison with risk calculated for the accident scenarios triggered by natural events.

\section{[INSERT FIGURE 4 HERE]}

\section{Results and Discussion}

\subsection{Results}

The methodology for the implementation of NaTech scenarios in QRA studies was applied to the analysis of the four reference flood events considered. Table 8 shows the release frequencies obtained from the equipment vulnerability models on the basis of the reference flood scenarios and the equipment geometrical data. For atmospheric tanks, the approach summarized in Table 1 was applied, thus determining the Critical Filling Level (CFL) as a function of the stored substance, tank geometry and flooding conditions. As shown in the table, for all the flooding conditions considered, the failure of the atmospheric tanks resulted credible. The failure probabilities calculated ranged from $1-5 \%$ to $15-20 \%$ respectively for the low and the high severity flood scenarios.

In the case of pressurized horizontal vessel, completely different data were obtained. For these vessels the fragility model described in Table 2 was applied. As shown in Table 8, even in presence of a high flood wave velocity, $v_{w}$, in none of the case studies the critical velocity $v_{w, c}$ exceeded the values $v_{w}$ considered. Hence, tank failure probability was evaluated only according to the estimated CFL, resulting in high values for Case 1 (up to $100 \%$ failure probability), while for the remaining cases low values were obtained (down to $0 \%$ failure probability in Case 4). This was due to the fact that the tanks were considered anchored to concrete supports, that limited the lift force associated to the flood.

\section{[INSERT TABLE 8 HERE]}

On the basis of equipment failure probabilities, the application of the detailed procedure for NaTech quantitative risk assessment discussed in Section 2.3 allowed for the calculation of the frequencies and probabilities of scenarios involving the simultaneous damage of more than one equipment item. For the sake of simplicity, scenarios resulting from the damage of each equipment item were assumed to cause the same consequences as those calculated for conventional risk assessment.

Fig. 5 shows the results of quantitative risk assessment in the presence of NaTech scenarios in terms of local specific individual risk (LSIR) contours associated to the four considered case studies.

\section{[INSERT FIGURE 5 HERE]}

\section{[INSERT TABLE 9 HERE]}

Case 1, in which a high depth of flood water is assumed (see Table 6), resulted the more critical flood event, leading to the highest number of damaged vessels and of accident scenarios. On the basis of the failure frequencies estimated from the equipment vulnerability models, about 30000 scenarios (over a total number of $2^{32}-1$ possible combinations) resulted in a frequency value above the cut-off value of $10^{-10} 1 / \mathrm{y}$, but only 11000 of them contribute significantly to the overall risk. For the sake of simplicity, a summary of the scenarios triggered by the reference flood event in Case 1 are reported in Table 9, where also their description and expected simultaneous final outcomes are described.

The second reference flood event (Case 2), that can be considered as a flash-flood due to its high water speed and limited depth (see Table 5), does not contribute significantly to the risk indexes 
because several equipment items (and especially pressurized vessels) are mounted on concrete supports having a height comparable to the maximum flood water depth considered. Thus, only for the atmospheric tanks damages were possible and only 512 scenarios resulted significant. Among them, only 185 were above the threshold value, as summarized in Table 9. Moreover their final consequences were much less severe than those of scenarios arising for the reference flood of Case 1.

In Case 3, the effects of a flood of intermediate severity (and expected return time) were analyzed. Even if pressurized tanks from P1 to P9 and from P18 to P23 were not affected by the flood wave, due to the low height assumed for the flood water, more than 500000 scenarios were analyzed. A summary of their main features is reported in Table 9, where the scenarios that mainly contribute to the overall NaTech risk increase are evidenced.

Finally, in Case 4, a low severity flood event was considered. Thus, the number of scenarios was lower than that of the other cases. Nevertheless, as shown in Table 9, slightly higher frequencies were evaluated, due to the lower return time assumed for the flood event (see Table 6).

When the increase in individual risk due to flood-triggered NaTech scenarios is considered, it is quite clear that the contribution due to the reference flood event considered in Case 1 is much higher than for other cases, as evident from the comparison of the different panels in Fig. 5. Moreover, individual risk values increase up to three order of magnitude with respect to those obtained considering only conventional scenarios, mainly due to the fact that typical flood frequencies calculated on the basis of the expected return times are higher than the typical baseline frequencies for technological accidents. This is confirmed by the values calculated for the Potential Life Loss (PLL), that increased from $8.84 \times 10^{-3}$ fatalities/y to 14.8 fatalities/y when including NaTech events due to their higher frequency and severity if compared to conventional accidents.

Societal risk was also calculated considering the population distribution around the industrial area. In the case of flood-induced NaTech scenarios, the conservative assumption that population distribution will not change during a flood was introduced in the calculations. Only the toxic cloud dispersion of chlorine from the rupture of pressurized vessels P21, P22 and P23 resulted in physical effects sufficiently high to cause harm in the areas where the resident population was present. Since only reference flood event considered for Case 1 was sufficiently severe to affect these vessels, this was the only flood event that caused changes in the overall societal risk value, as shown in Fig. 6 that reports the F/N curves. Fig. 6 shows the comparison of the F/N curve for societal risk calculated considering the flood events with respect to that obtained considering only for conventional failures. The F/N curve obtained considering NaTech events is mainly influenced by the increse in the frequency of loss of containment from chlorine tanks (P21-P23, see Fig. 2a for tank position in the lay-out). The $\mathrm{F} / \mathrm{N}$ curve obtained considering NaTech scenarios also shows some additional steps at high $\mathrm{N}$ values ( $\mathrm{N}$ values higher than 4000 ) due to the presence of "combined scenarios", where the impact of the simultaneous failure of the chlorine tanks caused by the flood event is considered.

\section{[INSERT FIGURE 6 HERE]}

\subsection{Discussion}

The analysis of the case studies demonstrated that a high impact on the risk profile of industrial facilities storing and processing hazardous materials may be associated to NaTech scenarios caused by flood events. Despite the low values calculated for vessel failure probability (see Table 8 ), rather high values of accident frequencies were obtained due to the high frequency of flood events estimated on the basis of the return time. This issue was also pointed out in previous studies [26,27], in which NaTech frequencies were compared with baseline frequency values used for component failure in "conventional" QRA. This is due to the fact that, in flood-prone zones, flooding frequencies may reach values that are orders of magnitude higher with respect to those 
related to component failures due to internal causes (e.g., mechanical failure, corrosion, erosion, rupture induced by vibrations, etc.).

The present paper is the first study presenting a quantitative risk assessment of NaTech scenarios triggered by floods involving both atmospheric and pressurized storage tanks. Such results, obtained by the integration of a methodology for the QRA of NaTech scenarios and recently developed specific vulnerability models, allow for the first time a detailed analysis of risk increase and the assessment of the risk caused by different flood scenarios. The results also allow informed decision making concerning flood protection and safety barriers in industrial facilities were hazardous substances are present.

Atmospheric tanks demonstrated to be the more vulnerable tank category, with possible failures even in presence of low severity flooding conditions (e.g., see the results for Case 4 in Table 8). With respect to horizontal pressurized vessels, the results obtained show that, depending on the type of expected flood scenario, an increase in the height of the support may be considered as a possible effective protection barrier. In fact, no failure was predicted for low water depth flood events (Case 2 ) even with high flood velocities (see Table 8). In the absence of the concrete support considered, a high failure probability would have been predicted by the vulnerability model, with a potential critical impact on the risk profile of the facility.

Therefore, the results of quantitative risk assessment allowed determining the more vulnerable equipment items and the units that may lead to more severe accidental scenarios. The case study exemplified an innovative risk-based approach aimed identifying the more critical items in the plant respect to several types of flooding events, that may affect a given geographical area. Hence, the results may be used to support informed decision making concerning flood protection and safety barriers in industrial facilities were hazardous substances are present.

In fact, risk assessment results may provide relevant information for the design of supports and anchorage of safety-critical units, as those storing or processing flammable or toxic liquefied gases under pressure. A tank can be mounted on higher pedestals or providing curbs, or it can be anchored by attaching it to concrete slabs heavy enough to resist the force of flood waters or by running straps over it and attaching them to ground anchors [50,51]. However, the protection design should take into account both parameters related to the credible flooding scenarios and the resistance of the vessel.

Concerning the analysis of societal risk, NaTech may increase the frequency of accidental scenarios but also the related severity, due to the possibility of multiple equipment failures induced by flood. This was pointed out by Fig. 6, where the F/N curve shows the impact of the scenarios due to simultaneous multiple equipment failure caused by the flood.

Finally, it is also worth to point out that the extremely high severity of societal risk (see Fig. 6) was also due to the assumption that no modification in the population presence probability was considered. Actually, on one hand in the case of flash floods or floods caused by the sudden rupture of river levees, no time is usually available for evacuation, thus the results obtained may be considered realistic. On the other hand, in the case of long rivers where forecasting models are available, flood events due to heavy rains or to other adverse weather conditions may be anticipated of several hours or even of days. Thus, in the case of such flood scenarios there may be time for early warning and evacuation of population and workers, that may significantly change the number of persons exposed to the effects of the flood and of flood-induced NaTech scenarios. Thus, the final consequences of flood-induced NaTech scenarios may be different if the evacuation of population is considered. At the same time, a high concern is posed to emergency and rescue teams which should operate rescuing the population in areas near to industrial sites, that may be affected by the release of hazardous substances caused by NaTech scenarios, and that may need a specific training. 


\section{Conclusions}

The integration of a methodology for the assessment of risk contribution associated to NaTech scenarios triggered by floods with detailed equipment vulnerability models was presented. The results allowed a detailed insight of risk due to NaTech events triggered by floods. In particular, the higher severity of specific NaTech scenarios involving the simultaneous failure of multiple equipment items was evidenced and the effects on societal risk were captured by $\mathrm{F} / \mathrm{N}$ curves. The straightforward identification of critical units by individual risk assessment allows quantifying the effect of safety barriers. The results support both risk informed decision making concerning protection systems and the development of new criteria addressing the appropriate design of the vessel supports and basements to limit the potential impact of floods on critical process and storage units in flood-prone areas.

\section{Acknowledgements}

The authors gratefully acknowledge financial support received from the EC within the 7th FP TOSCA project.

\section{References}

[1] Young S, Balluz L, Malilay J. Natural and technologic hazardous material releases during and after natural disasters: a review. Science of the Total Environment 2004;322:3-20.

[2] Showalter PS, Myers MF. Natural disasters in the United-States as release agents of oil, chemicals, or radiological materials between 1980 and 1989. Risk Analysis 1994;14:16981.

[3] Rasmussen K. Natural events and accidents with hazardous materials. J Hazard Mater 1995;40:43-54.

[4] Krausmann E, Cozzani V, Salzano E, Renni E. Industrial accidents triggered by natural hazards: an emerging risk issue. Nat Hazards Earth Syst Sci 2011;11:921-9.

[5] Petrova EG, Krausmann E. From natural hazards to technological disasters. Nat Hazards Earth Syst Sci 2011;11:3063-5.

[6] Cozzani V, Campedel M, Renni E, Krausmann E. Industrial accidents triggered by flood events: Analysis of past accidents. J Hazard Mater 2010;175:501-9.

[7] Krausmann E, Renni E, Campedel M, Cozzani V. Industrial accidents triggered by earthquakes, floods and lightning: lessons learned from a database analysis. Nat Hazards 2011;59:285-300.

[8] Renni E, Krausmann E, Cozzani V. Industrial accidents triggered by lightning. J Hazard Mater 2010;184:42-8.

[9] Cruz AM, Okada N. Methodology for preliminary assessment of Natech risk in urban areas. Nat Hazards 2008;46:199-220.

[10] Krausmann E, Cruz AM. Natech disasters: when natural hazards trigger technological accidents. Nat Hazards 2008;46:139-263.

[11] Cruz AM, Okada N. Consideration of natural hazards in the design and risk management of industrial facilities. Nat Hazards 2008;44:213-27.

[12] Cruz AM, Steinberg LJ, Vetere-Arellano L. Emerging issues for natech disaster risk management in Europe. J Risk Res 2006;9:483-501.

[13] Fendler R. Floods and safety of establishments and installations containing hazardous substances - Conclusions on a Research Project of the German Umweltbundesamt. Nat Hazards 2008;46:257-63. 
[14] Necci A, Argenti F, Landucci G, Cozzani V. Accident scenarios triggered by lightning strike on atmospheric storage tanks . Reliab Eng Syst Saf 2014;127:30-46.

[15] Busini V, Marzo E, Callioni A, Rota R. Definition of a short-cut methodology for assessing earthquake-related Na-Tech risk. J Hazard Mater 2011;192:329-39.

[16] Salzano E, Iervolino I, Fabbrocino G. Seismic risk of atmospheric storage tanks in the framework of quantitative risk analysis. J Loss Prev Process Ind 2003;16:403-9.

[17] Salzano E, Garcia Agreda A, Di Carluccio A, Fabbrocino G. Risk assessment and early warning systems for industrial facilities in seismic zones. Reliab Eng Syst Saf 2009;94:1577-84.

[18] Milazzo MF, Ancione G, Basco A, Lister DG, Salzano E, Maschio G. Potential loading damage to industrial storage tanks due to volcanic ash fallout. Natural Hazards 2013;66:939-953.

[19] Krausmann E, Mushtaq F. A qualitative Natech damage scale for the impact of floods on selected industrial facilities. Natural Hazards 2008;46:939-953.

[20] Krausmann E, Cruz AM. Impact of the 11 March 2011, Great East Japan earthquake and tsunami on the chemical industry. Nat Hazards 2013;67:811-828.

[21] Antonioni G, Bonvicini S, Spadoni G, Cozzani V. Development of a frame work for the risk assessment of Na-Tech accidental events. Reliab Eng Syst Saf 2009;94:1442-50.

[22] Antonioni G, Spadoni G, Cozzani V. A methodology for the quantitative risk assessment of major accidents triggered by seismic events. J Hazard Mater 2007;147:48-59.

[23] Campedel M, Cozzani V, Garcia-Agreda A, Salzano E. Extending the quantitative assessment of industrial risks to earthquake effects. Risk Analysis 2008;28:1231-46.

[24] Landucci G, Gubinelli G, Antonioni G, Cozzani V. The assessment of the damage probability of storage tanks in domino events triggered by fire. Accid Analysis Prev 2009;41:1206-15.

[25] Cozzani V, Gubinelli G, Antonioni G, Spadoni G, Zanelli S. The assessment of risk caused by domino effect in quantitative area risk analysis. J Hazard Mater 2005;127:14-30.

[26] Landucci G, Antonioni G, Tugnoli A, Cozzani V. Release of hazardous substances in flood events: damage model for atmospheric storage tanks. Reliab Eng Syst Saf 2012;106:200-16.

[27] Landucci G, Necci A, Antonioni G, Tugnoli A, Cozzani V. Release of hazardous substances in flood events: damage model for horizontal cylindrical vessels. Reliab Eng Syst Saf 2014; 132:125-45.

[28] Landucci G., Necci A., Tugnoli A., Antonioni G., Cozzani V. Natech scenarios caused by flooding: evaluation of accident frequency by the use of fragility models, Chemical Engineering Transactions 2014;36:427-432 DOI: 10.3303/CET1436072

[29] Charlton R. Fundamentals of fluvial geomorphology. Abingdon, Oxon: Routledge; 2008.

[30] Bryant E. Natural Hazards. New York: Cambridge University Press; 2005.

[31] New South Wales Government. Floodplain Development Manual: the management of flood liable land, Appendix L "Hydraulic and Hazard Categorization". Sydney: Dept. of Infrastructure, Planning and Natural Resources; 2005.

[32] Rijkswaterstaat. Flood risks and safety in the Netherlands (Floris), Report DWW-2006-014. Delft: Rijkswaterstaat, Dutch Ministry of Infrastructure and Environment; 2005.

[33] Holmes RR Jr. Field methods for hydrologic and environmental studies. In: Holmes RR Jr., Terrio PJ, Harris MA, Mills PC editors, Introduction to field methods for hydrologic and environmental studies, Open-File Report 01-50, Urbana: US Department of Interior U.S. Geological Survey; 2001, p. 1-75. Available at http://il.water.usgs.gov/pubs/ofr0150_chapter1.pdf

[34] Department of Regional Development and Environment Executive Secretariat for Economic and Social Affairs Organization of American States. Primer on Natural Hazard Management in Integrated Regional Development Planning. Washington, D.C.: Dept. of Regional 
Development and Environment, Executive Secretariat for Economic and Social Affairs, Organization of American States; 1991.

[35] Mannan S. Lees' loss prevention in the process industries, 3rd ed. Oxford (UK): Elsevier; 2005.

[36] Center for Chemical Process Safety. Guidelines for chemical process quantitative risk analysis, 2nd ed. New York (NY): American Institute of Chemical Engineers; 2000.

[37] Van Den Bosh CJH, Weterings RAPM. Methods for the calculation of physical effects (Yellow Book), 3rd ed. The Hague (The Netherlands): Committee for the Prevention of Disasters; 2005

[38] Cozzani V, Antonioni G, Landucci G, Tugnoli A, Bonvicini S, Spadoni G. Quantitative assessment of domino and NaTech scenarios in complex industrial areas. J Loss Prev Process Ind. 2014;28:10-22.

[39] Campedel M. Analysis of major industrial accidents triggered by natural events reported in the principal available chemical accident databases. Report EUR 23391 EN. Ispra (I): Commission of the European Communities; 2008.

[40] U.S. Army Corps of Engineers. The great flood of 1993 post-flood report: Upper Mississippi River and lower Missouri River basins. St. Louis: U.S. Army Corps of Engineers; 1993.

[41] Gruntfest E, Pollack D. Warnings, mitigation, and litigation: Lessons for research from the 1993 flood. Update Water Resources 1994;95:40-5.

[42] Irwin JS. A theoretical variation of the wind profile power-law exponent as a function of surface roughness and stability. Atmos Environ 1967;13(1):191-4

[43] Chamberlain AC. Roughness length of sea, sand, and snow. Boundary-Layer Meteorology 1983;25(4):405-9.

[44] Uijt de Haag PAM, Ale BJM. Guidelines for quantitative risk assessment (Purple Book). The Hague: Committee for the Prevention of Disasters; 1999.

[45] Reniers G, Cozzani V (Eds). Domino effects in the process industries. Modelling, prevention and managing. Amsterdam (The Netherlands): Elsevier; 2013.

[46] Antonioni G, Cozzani V, Gubinelli G, Spadoni G, Zanelli S. The estimation of vulnerability in domino accidental events. In: Proc. Eur. Conf. Safety and Reliability, London (K): Springer, pp. 3653 - 3658; 2004.

[47] Bonvicini S, Ganapini S, Spadoni G, Cozzani V. The description of population vulnerability in Quantitative Risk Analysis. Risk Analysis 2012;32:1576-1594.

[48] Spadoni G, Egidi D, Contini S. Through ARIPAR-GIS the quantified area risk analysis supports land-use planning activities. J Hazard Mater 2000;71(1-3):423-437.

[49] Spadoni G, Contini S, Uguccioni G. The new version of ARIPAR and the benefits given in assessing and managing major risks in industrialised areas. Proc Safety Environ Prot 2003;81(1):19-30.

[50] Haney C. Actions to be taken in response to the Hurricane. Lessons Learned Task Force Report (WITS No. 200600198, TAC No. MD1832). In: Leach, M.N. (Ed.), US Nuclear Regulatory Commission, p. 30, 2006

[51] Kopytko N, Perkins J. Climate change, nuclear power, and the adaptation-mitigation dilemma. Energy Policy 2011;39(1):318-33.

\section{List of table captions}

Table 1: Vulnerability model and input parameters for atmospheric cylindrical tanks involved in flooding events [26]. CFL: critical filling level.

Table 2: Vulnerability model and input parameters for horizontal cylindrical tanks involved in flooding events [27]. 
Table 3: Summary of the methodology for the identification of credible combinations of events and the resultant frequency (step 7 and step 8) and consequence evaluation for multiple failures (step 9) applied in the present work (see Fig. 1). For more details see [21,22].

Table 4: Main features of the vessels considered in the present study. Ambient temperature considered: $293 \mathrm{~K}$.

Table 5: Resident population presence probabilities considered in the case study.

Table 6: Flood reference scenarios defined for the case-study.

Table 7: Final outcomes considered for the QRA of conventional release events.

Table 8: Vessel failure probability and frequency of loss of containment calculated for the four flood reference scenarios considered in the case study.

Table 9: Frequencies of flood-triggered scenarios.

\section{List of figure captions}

Figure 1: Methodology for the quantitative risk assessment of NaTech scenarios.

Figure 2: Layout considered for the case study: a) overview of the industrial area, position of the tank farms and location of pressurized tanks P21-P23; b) pressurized tank farm and storage tank $\mathrm{S} 1 ; \mathrm{c})$ atmospheric tank farm.

Figure 3: Density of the resident population surrounding the industrial area.

Figure 4: Individual risk contours (1/y) calculated for accident scenarios deriving from conventional release events due to internal failures.

Figure 5: Individual risk contours (1/y) due to flood-triggered accidents: a) Case 1, b) Case 2, c) Case 3, d) Case 4.

Figure 6: Societal risk $\mathrm{F} / \mathrm{N}$ curves evaluated for the conventional scenarios due to internal failures and for Case 1 reference flood scenario (NaTech). 


\section{TABLES}

Table 1: Vulnerability model and input parameters for atmospheric cylindrical tanks involved in flooding events [26,28]. CFL: critical filling level.

\begin{tabular}{|c|c|c|}
\hline Item & Definition & Value/Equation \\
\hline \multicolumn{3}{|c|}{ Vulnerability model equations } \\
\hline $\mathrm{CFL}_{\mathrm{v}}$ & $\begin{array}{l}\text { Critical Filling Level for vertical } \\
\text { atmospheric vessels }\end{array}$ & $C F L_{v}=\left(\frac{\rho_{w} k_{w}}{2} v_{w}^{2}+\rho_{w} g h_{w}-P_{c r}\right) / \rho_{f} g H$ \\
\hline $\mathrm{P}_{\mathrm{cr}}$ & $\begin{array}{l}\text { Vessel critical pressure evaluated with the } \\
\text { proposed simplified correlation }\end{array}$ & $\begin{array}{l}P_{c r}=J_{1} C+J_{2} \text { in which } \\
\mathrm{J}_{1}=-0-199 \\
\mathrm{~J}_{2}=6950\end{array}$ \\
\hline$\Psi$ & Vessel vulnerability due to flooding & $\Psi=\left(C F L-\phi_{\min }\right) /\left(\phi_{\max }-\phi_{\min }\right)$ \\
\hline \multicolumn{3}{|c|}{ Input parameters } \\
\hline $\mathrm{C}$ & Vessel capacity & $\begin{array}{l}\text { Small capacity } C<5000 \mathrm{~m}^{3} \\
\text { Medium capacity } 5000-10000 \mathrm{~m}^{3} \\
\text { Large capacity }>10000 \mathrm{~m}^{3}\end{array}$ \\
\hline $\mathrm{v}_{\mathrm{w}}$ & Flood water speed* & $0-3.5 \mathrm{~m} / \mathrm{s}$ \\
\hline $\mathrm{h}_{\mathrm{w}}$ & Flood water depth* & $0-4 \mathrm{~m}$ \\
\hline$\rho_{\mathrm{w}}$ & Flood water density & $1100 \mathrm{~kg} / \mathrm{m}^{3}$ \\
\hline$\rho_{\mathrm{f}}$ & Stored liquid density & $650-1300 \mathrm{~kg} / \mathrm{m}^{3}$ \\
\hline $\mathrm{k}_{\mathrm{w}}$ & Hydrodynamic coefficient & 1.8 \\
\hline $\mathrm{H}$ & Vessel height & $\begin{array}{l}\text { Small capacity } 3.6-18 \mathrm{~m} \\
\text { Medium capacity } 3.6-16.2 \mathrm{~m} \\
\text { Large capacity } 3.6-7.2 \mathrm{~m}\end{array}$ \\
\hline g & Gravity acceleration & $9.81 \mathrm{~m} / \mathrm{s}^{2}$ \\
\hline$\phi_{\min }$ & Minimum operative filling level & 0.01 \\
\hline$\phi_{\max }$ & Maximum operative filling level & 0.75 \\
\hline
\end{tabular}

* Parameters may be derived from the hydrogeological study of the analyzed area or given by local competent authorities. 
Table 2: Vulnerability model and input parameters for horizontal cylindrical tanks involved in flooding events [27].

Item Definition

Vulnerability model equations

$\mathrm{CFL}_{h} \quad$ Critical Filling Level for horizontal vessels (pressurized or atmospheric)

$\mathrm{v}_{\mathrm{w}, \mathrm{c}} \quad$ Flooding critical velocity

$\Psi \quad$ Vessel vulnerability due to flooding

\section{Input parameters}

C Vessel capacity

$\mathrm{W}_{\mathrm{t}} \quad$ Vessel tare weight*

D Vessel diameter

L Vessel length

A First $\mathrm{CFL}_{\mathrm{h}}$ correlation coefficient

B Second $\mathrm{CFL}_{\mathrm{h}}$ correlation coefficient

E $\quad \mathrm{v}_{\mathrm{w}, \mathrm{c}}$ correlation factor

$\mathrm{F} \quad \mathrm{V}_{\mathrm{w}, \mathrm{c}}$ correlation exponent

K1 Coefficient for A evaluation*

K2 Coefficient for B evaluation*

K3 Coefficient for B evaluation*

K4 Coefficient for E evaluation*

K5 Coefficient for F evaluation*

K6 Coefficient for $\mathrm{F}$ evaluation*

a Exponent for A evaluation*

b Exponent for B evaluation*

c Exponent for E evaluation

$\mathrm{v}_{\mathrm{w}} \quad$ Flood water speed $* *$

$\mathrm{h}_{\mathrm{w}} \quad$ Flood water depth**

$\rho_{\mathrm{w}} \quad$ Flood water density

$\mathrm{h}_{\mathrm{c}} \quad$ Height of concrete basement (flooding protection)

$\mathrm{h}_{\min } \quad$ Minimum flooding height able to wet the vessel surface

$\lambda \quad$ Saddle height parameter which indicates the vessel axis height respect to the ground anchorage point

$\rho_{\mathrm{l}} \quad$ Stored liquid density

$\rho_{\mathrm{v}} \quad$ Stored vapours density

Reference density used for the definition of CFL

$\rho_{\text {ref }} \quad$ correlations

$\phi_{\min } \quad$ Minimum operative filling level

$\phi_{\max } \quad$ Maximum operative filling level

* Value evaluated for $2 \mathrm{MPa}$ design pressure;

** Parameters may be derived from the hydrogeological study of the analyzed area or given by local competent authorities.

\section{Value/Equation}

$$
\begin{aligned}
& C F L_{h}=\left(\rho_{r e f} \cdot A\right) /\left(\rho_{l}-\rho_{v}\right) \cdot\left(h_{w}-h_{c}\right)+\left(\rho_{r e f} \cdot B-\rho_{v}\right) /\left(\rho_{l}-\rho_{v}\right) \\
& v_{w, c}=E \cdot\left(h_{w}-h_{c}-h_{\min }\right)^{F} \\
& \text { If } v_{w} \geq v_{w, c,} \Psi=1 ; \\
& \text { If } v_{w}<v_{w, c,} \Psi=\left(C F L-\phi_{\min }\right) /\left(\phi_{\max }-\phi_{\min }\right)
\end{aligned}
$$

Small capacity $<10 \mathrm{~m}^{3}$

Medium capacity $10-30 \mathrm{~m}^{3}$

Large capacity $>30 \mathrm{~m}^{3}$

900-2200 kg (Small capacity)

$3000-7200 \mathrm{~kg}$ (Medium capacity)

9900-63000 kg (Large capacity)

1.3-1.6 m (Small capacity)

1.6-2.4 m (Medium capacity)

2.3-3.8 m (Large capacity)

3-3.5 m (Small capacity)

4.5-11.1 m (Medium capacity)

8-24 m (Large capacity)

$A=K_{1} \cdot D^{a}$

$B=K_{2}\left(W_{t}+K_{3}\right)^{b}$

$E=K_{4} \cdot L^{c}$

$F=K_{5} \ln (L / D)+K_{6}$

1.339

$-1.21$

$-374.4$

5.497

$-0.06$

$-0.375$

$-0.989$

$-0.107$

$-0.692$

$0-3.5 \mathrm{~m} / \mathrm{s}$

$0-4 \mathrm{~m}$

$1100 \mathrm{~kg} / \mathrm{m}^{3}$

$0.25 \mathrm{~m}$ (assumed for the present study)

$h_{\text {min }}=\lambda-D / 2$

$0.98 \mathrm{~m}$ (Small capacity)

0.98-1.38 m (Medium capacity)

$1.38-1.98 \mathrm{~m}$ (Large capacity)

$500-1100 \mathrm{~kg} / \mathrm{m}^{3}$

$1.25-20 \mathrm{~kg} / \mathrm{m}^{3}$

$1000 \mathrm{~kg} / \mathrm{m}^{3}$

0.01

0.90 
Table 3: Summary of the methodology for the identification of credible combinations of events and the resultant frequency (step 7 and step 8) and consequence evaluation for multiple failures (step 9) applied in the present work (see Fig. 1). For more details see [21,22].

\begin{tabular}{|c|c|c|}
\hline Item & Definition & Value/Equation \\
\hline \multicolumn{3}{|c|}{ Input parameters } \\
\hline $\mathrm{n}$ & Total number of target equipment & - \\
\hline $\mathrm{k}$ & $\begin{array}{l}\text { Number of target equipment simultaneously } \\
\text { damaged by a flooding scenario }\end{array}$ & - \\
\hline $\mathrm{N}_{\mathrm{k}}$ & $\begin{array}{l}\text { Number of flooding induced scenarios } \\
\text { involving k different final outcomes }\end{array}$ & $N_{k}=\left(\begin{array}{l}k \\
n\end{array}\right)=\frac{n !}{(n-k) ! k !}$ \\
\hline $\mathrm{m}$ & $\begin{array}{l}\text { Index associated to a generic combination } \\
\text { of } k \text { events }\end{array}$ & $\mathrm{m}=1, \ldots, \mathrm{N}_{\mathrm{k}}$ \\
\hline$\Psi$ & Vessel vulnerability due to flooding & $\begin{array}{l}\text { See Table } 1 \text { for vertical atmospheric vessels or } \\
\text { Table } 2 \text { for horizontal vessels }\end{array}$ \\
\hline $\mathrm{f}$ & $\begin{array}{l}\text { Overall expected frequency of the flooding } \\
\text { scenario affecting the industrial facility }\end{array}$ & Evaluated according to Eq. (1) \\
\hline$\delta\left(\mathrm{i}, \mathbf{J}^{\mathrm{k}}{ }_{\mathrm{m}}\right)$ & Combination index & $\begin{array}{l}\delta\left(i, \mathbf{J}^{\mathrm{k}}\right)=1 \text { if } \mathrm{i} \text {-th event triggered by flooding } \\
\text { belongs to the vector } \mathbf{J}_{\mathrm{m}}^{\mathrm{k}} \\
\delta\left(\mathrm{i}, \mathbf{J}^{\mathrm{k}}{ }_{\mathrm{m}}\right)=0 \text { if not. }\end{array}$ \\
\hline \multicolumn{3}{|c|}{ Evaluation of combinations probability and frequency } \\
\hline $\mathrm{N}_{\mathrm{f}}$ & $\begin{array}{l}\text { Number of different overall scenarios that } \\
\text { may be generated by a single flooding } \\
\text { condition }\end{array}$ & $N_{f}=\sum_{k=1}^{n}\left(\begin{array}{l}n \\
k\end{array}\right)=2^{n}-1$ \\
\hline$P_{f}^{(k, m)}$ & $\begin{array}{l}\text { Probability of occurrence of the m-th } \\
\text { combination involving the simultaneous } \\
\text { damage of k equipment }\end{array}$ & $P_{f}^{(k, m)}=\prod_{i=1}^{n}\left[1-\psi+\delta\left(i, \mathbf{J}_{m}^{k}\right)(2 \psi-1)\right]$ \\
\hline$f_{f}^{(k, m)}$ & $\begin{array}{l}\text { Frequency of occurrence of the } m \text {-th } \\
\text { combination involving the simultaneous } \\
\text { damage of k equipment }\end{array}$ & $f_{f}^{(k, m)}=f \cdot P_{f}^{(k, m)}$ \\
\hline \multicolumn{3}{|c|}{ Consequence assessment trough the vulnerability evaluation of multiple scenarios } \\
\hline $\mathrm{V}_{\mathrm{f}, \mathrm{i}}$ & $\begin{array}{l}\text { Vulnerability calculated for the }(\mathrm{k}, \mathrm{m}) \\
\text { scenario triggered by flooding }\end{array}$ & \\
\hline$V_{f}^{(k, m)}$ & $\begin{array}{l}\text { Vulnerability associated to the occurrence } \\
\text { of the m-th combination involving the } \\
\text { simultaneous damage of k equipment }\end{array}$ & $V_{f}^{(k, m)}=\min \left[\sum_{i=1}^{m} V_{f, i} ; 1\right]$ \\
\hline
\end{tabular}


Table 4: Main features of the vessels considered in the present study. Ambient temperature considered: $293 \mathrm{~K}$.

\begin{tabular}{|c|c|c|c|c|c|c|c|c|}
\hline \multirow{2}{*}{ Vessel features } & \multicolumn{5}{|c|}{ Pressurized vessels } & \multicolumn{3}{|c|}{ Atmospheric vessels } \\
\hline & P1 to P9 & P10 to P16 & $\mathbf{P 1 7}$ & P18 to P20 & P21 to P23 & S1 & T1-T4 & T5-T8 \\
\hline Nominal capacity $\left(\mathrm{m}^{3}\right)$ & 50 & 30 & 115 & 150 & 100 & 3179 & 6511 & 6511 \\
\hline Diameter $(\mathrm{m})$ & 2.7 & 2.4 & 2.75 & 3.2 & 2.8 & 15 & 24 & 24 \\
\hline Lenght $^{\mathrm{a}} /$ Height $^{\mathrm{b}}(\mathrm{m})$ & 10 & 6.5 & 20.1 & 19.4 & 18 & 18 & 14.4 & 14.4 \\
\hline Shell thickness (mm) & 23 & 21 & 24 & 27 & 24 & 12.5 & 12.5 & 12.5 \\
\hline Vessel tare weight (metric ton) & 12.3 & 5.9 & 29.2 & 36.1 & 26.2 & 110 & 165 & 165 \\
\hline Saddle parameter $(\mathrm{m})$ & 1.48 & 1.38 & 1.58 & 1.78 & 1.58 & - & - & - \\
\hline Filling level & $90 \%$ & $90 \%$ & $90 \%$ & $90 \%$ & $90 \%$ & $75 \%$ & $75 \%$ & $75 \%$ \\
\hline Substance contained & Propylene & Propane & $\mathrm{LPG}^{\mathrm{c}}$ & Ammonia & Chlorine & Organic solvent & Gasoline & Benzene \\
\hline Physical state & Liquefied gad & Liquefied gad & Liquefied gad & Liquefied gad & Liquefied gad & Liquid & Liquid & Liquid \\
\hline Pressure (bar) & 8 & 8.5 & 2 & 8.5 & 6.7 & 1.05 & 1.05 & 1.05 \\
\hline Liquid density $\left(\mathrm{kg} / \mathrm{m}^{3}\right)$ & 615 & 450 & 550 & 600 & 1400 & 650 & 750 & 877 \\
\hline Vapor density $\left(\mathrm{kg} / \mathrm{m}^{3}\right)$ & 13.8 & 15.4 & 4.8 & 4.9 & 19.3 & $0.97^{\mathrm{d}}$ & $0.97^{\mathrm{d}}$ & $0.97^{\mathrm{d}}$ \\
\hline Inventory (metric ton) & 32 & 12 & 59 & 84 & 140 & 1550 & 3656 & 4275 \\
\hline
\end{tabular}

a: horizontal vessels; b: vertical vessel; c: assumed as pure butane; d: average density of the purge gas (e.g., nitrogen blanketing), not relevant for model application. 
Table 5: Resident population presence probabilities considered in the case study.

\begin{tabular}{|c|c|c|c|}
\hline Period & Presence probability & Indoor & Outdoor \\
\hline Spring-summer/day & $45 \%$ & $93 \%$ & $7 \%$ \\
\hline Spring-summer/night & $85 \%$ & $99 \%$ & $1 \%$ \\
\hline Autumn-winter/day & $53 \%$ & $93 \%$ & $7 \%$ \\
\hline Autumn-winter/night & $100 \%$ & $99 \%$ & $1 \%$ \\
\hline
\end{tabular}

Table 6: Flood reference scenarios defined for the case-study.

\begin{tabular}{|c|c|c|c|c|}
\hline $\begin{array}{c}\text { Flooding } \\
\text { conditions }\end{array}$ & $\begin{array}{c}\text { Return time } \\
(\mathbf{y})\end{array}$ & $\begin{array}{c}\text { Flooding } \\
\text { frequency }(\mathbf{1} / \mathbf{y})\end{array}$ & $\begin{array}{c}\text { Flooding } \\
\text { depth }(\mathbf{m})\end{array}$ & $\begin{array}{c}\text { Flooding } \\
\text { velocity }(\mathbf{m} / \mathbf{s})\end{array}$ \\
\hline CASE 1 & 500 & $2.0 \times 10^{-3}$ & 2.00 & 0.5 \\
\hline CASE 2 & 500 & $2.0 \times 10^{-3}$ & 0.50 & 2 \\
\hline CASE 3 & 200 & $5.0 \times 10^{-3}$ & 1.15 & 0.75 \\
\hline CASE 4 & 30 & $3.33 \times 10^{-2}$ & 0.75 & 0.5 \\
\hline
\end{tabular}

Table 7: Final outcomes considered for the QRA of conventional release events.

\begin{tabular}{|l|l|l|l|}
\hline Tank ID & LOC & Final outcome & Frequency (1/y) \\
\hline T1 to T8, and S1 & $\begin{array}{l}\text { Instantaneous release } \\
\text { in the catch basin of } \\
\text { the total inventory }\end{array}$ & Pool fire & $4.5 \times 10^{-6}$ \\
\hline P1 to P17 & $\begin{array}{l}\text { Release in 10 min of } \\
\text { the total inventory }\end{array}$ & $\begin{array}{l}\text { Flash fire of propane, } \\
\text { propylene or LPG }\end{array}$ & $4.5 \times 10^{-7}$ \\
\hline P18 to P23 & $\begin{array}{l}\text { Release in 10 min of } \\
\text { the total inventory }\end{array}$ & $\begin{array}{l}\text { Toxic cloud of } \\
\text { ammonia or chlorine }\end{array}$ & $5.0 \times 10^{-7}$ \\
\hline
\end{tabular}


Table 8: Vessel failure probability and frequency of loss of containment calculated for the four flood reference scenarios considered in the case study.

\begin{tabular}{llcccccccc}
\hline & \multicolumn{1}{c}{} & \multicolumn{3}{c}{ Pressurized vessels } & \multicolumn{3}{c}{ Atmospheric vessels } \\
\hline Frequency evaluation & P1 to P9 & P10 to P16 & P17 & P18 to P20 & P21 to P23 & S1 & T1-T4 & T5-T8 \\
\hline \multirow{2}{*}{ CASE 1} & $\mathrm{~V}_{\mathrm{w}, \mathrm{c}}(\mathrm{m} / \mathrm{s})$ & 0.90 & 1.24 & 0.56 & 0.57 & 0.60 & - & - & - \\
& $\mathrm{CFL}$ & 0.699 & 1.000 & 0.832 & 0.576 & 0.304 & 0.135 & 0.153 & 0.131 \\
& Vulnerability $(\%)$ & $77.4 \%$ & $100.0 \%$ & $92.3 \%$ & $63.6 \%$ & $33.0 \%$ & $16.9 \%$ & $19.3 \%$ & $16.3 \%$ \\
& Frequency (1/y) & $1.55 \times 10^{-3}$ & $2.00 \times 10^{-3}$ & $1.85 \times 10^{-3}$ & $1.27 \times 10^{-3}$ & $6.60 \times 10^{-4}$ & $3.38 \times 10^{-4}$ & $3.86 \times 10^{-4}$ & $3.26 \times 10^{-4}$ \\
\hline \multirow{2}{*}{ CASE 2} & $\mathrm{~V}_{\mathrm{w}, \mathrm{c}}(\mathrm{m} / \mathrm{s})$ & 2.92 & 4.78 & 3.19 & 2.55 & 2.71 & - & - & - \\
& $\mathrm{CFL}$ & 0.010 & 0.010 & 0.010 & 0.010 & 0.010 & 0.026 & 0.035 & 0.030 \\
& Vulnerability (\%) & $0.0 \%$ & $0.0 \%$ & $0.0 \%$ & $0.0 \%$ & $0.0 \%$ & $2.2 \%$ & $3.4 \%$ & $2.7 \%$ \\
& Frequency (1/y) & 0.0 & 0.0 & 0.0 & 0.0 & 0.0 & $4.45 \times 10^{-5}$ & $6.74 \times 10^{-5}$ & $5.37 \times 10^{-5}$ \\
\hline \multirow{2}{*}{ CASE 3} & $\mathrm{~V}_{\mathrm{w}, \mathrm{c}}(\mathrm{m} / \mathrm{s})$ & 1.25 & 1.73 & 0.82 & 0.82 & 0.87 & - & - & - \\
& CFL & 0.010 & 0.038 & 0.073 & 0.010 & 0.010 & 0.058 & 0.069 & 0.059 \\
& Vulnerability (\%) & $0.0 \%$ & $3.1 \%$ & $7.1 \%$ & $0.0 \%$ & $0.0 \%$ & $6.5 \%$ & $8.0 \%$ & $6.6 \%$ \\
& Frequency (1/y) & 0.0 & $1.56 \times 10^{-4}$ & $3.56 \times 10^{-4}$ & 0.0 & 0.0 & $3.24 \times 10^{-4}$ & $3.99 \times 10^{-4}$ & $3.31 \times 10^{-4}$ \\
\hline \multirow{2}{*}{ CASE 4} & $\mathrm{~V}_{\mathrm{w}, \mathrm{c}}(\mathrm{m} / \mathrm{s})$ & 1.39 & 1.92 & 0.93 & 0.93 & 0.98 & - & - & - \\
& CFL & 0.010 & 0.010 & 0.010 & 0.010 & 0.010 & 0.018 & 0.025 & 0.022 \\
& Vulnerability (\%) & $0.0 \%$ & $0.0 \%$ & $0.0 \%$ & $0.0 \%$ & $0.0 \%$ & $1.0 \%$ & $2.1 \%$ & $1.6 \%$ \\
& Frequency (1/y) & 0.0 & 0.0 & 0.0 & 0.0 & 0.0 & $3.43 \times 10^{-4}$ & $6.91 \times 10^{-4}$ & $5.26 \times 10^{-4}$ \\
\hline
\end{tabular}


Table 9: Frequencies of flood-triggered scenarios.

\begin{tabular}{|c|c|c|c|c|c|c|c|c|}
\hline \multirow[t]{2}{*}{ Case } & \multicolumn{6}{|c|}{ Group of tanks/vessels } & \multirow[b]{2}{*}{ Simultaneous final outcomes expected } & \multirow{2}{*}{$\begin{array}{l}\text { Cumulated } \\
\text { frequency } \\
(1 / y)\end{array}$} \\
\hline & P1-P9 & P10-P16 & P17 & P18-P20 & P21-P23 & $\begin{array}{l}\text { S1, T1-T4, } \\
\text { T5-T8 }\end{array}$ & & \\
\hline \multirow{6}{*}{ CASE 1} & $\bar{D}$ & $\mathrm{AD}$ & $\mathrm{AD}$ & $\mathrm{D}$ & ND & ND & Toxic cloud(s) of ammonia and flash fires & $3.42 \times 10^{-4}$ \\
\hline & $\mathrm{D}$ & $\mathrm{AD}$ & $\mathrm{AD}$ & $\mathrm{D}$ & ND & $\mathrm{D}$ & $\begin{array}{l}\text { Toxic cloud(s) of ammonia, flash fires and } \\
\text { pool fire(s) }\end{array}$ & $2.18 \times 10^{-4}$ \\
\hline & $\mathrm{D}$ & $\mathrm{AD}$ & $\mathrm{AD}$ & ND & ND & ND & Flash fires & $1.96 \times 10^{-4}$ \\
\hline & $\mathrm{D}$ & $\mathrm{AD}$ & $\mathrm{AD}$ & $\mathrm{D}$ & $\mathrm{D}$ & ND & $\begin{array}{l}\text { Toxic cloud(s) of ammonia and/or chlorine } \\
\text { and flash fires }\end{array}$ & $1.68 \times 10^{-4}$ \\
\hline & ND & $\mathrm{AD}$ & $\mathrm{AD}$ & $\mathrm{D}$ & ND & ND & Toxic cloud(s) of ammonia and flash fires & $9.98 \times 10^{-5}$ \\
\hline & $\mathrm{D}$ & $\mathrm{AD}$ & $\mathrm{AD}$ & ND & $\mathrm{D}$ & ND & Toxic cloud(s) of chlorine and flash fires & $9.63 \times 10^{-5}$ \\
\hline \multirow{3}{*}{ CASE 2} & ND & ND & ND & ND & ND & T1-T4 only & Pool fire(s) & $6.47 \times 10^{-5}$ \\
\hline & ND & ND & ND & ND & ND & T5-T8 only & Pool fire(s) & $5.10 \times 10^{-5}$ \\
\hline & ND & ND & ND & ND & ND & S1 & Pool fire & $4.14 \times 10^{-5}$ \\
\hline \multirow{6}{*}{ CASE 3} & ND & ND & ND & ND & ND & $\mathrm{D}$ & Pool fire(s) & $8.83 \times 10^{-4}$ \\
\hline & ND & ND & $\mathrm{AD}$ & ND & ND & ND & Flash Fire & $2.76 \times 10^{-4}$ \\
\hline & ND & $\mathrm{D}$ & ND & ND & ND & ND & Flash fires(s) & $1.16 \times 10^{-4}$ \\
\hline & ND & ND & $\mathrm{AD}$ & ND & ND & $\mathrm{D}$ & Flash fire and pool fire(s) & $6.28 \times 10^{-5}$ \\
\hline & ND & $\mathrm{D}$ & ND & ND & ND & $\mathrm{D}$ & Flash fire(s) and pool fire(s) & $2.63 \times 10^{-5}$ \\
\hline & ND & $\mathrm{D}$ & $\mathrm{AD}$ & ND & ND & ND & Flash Fire(s) & $8.84 \times 10^{-6}$ \\
\hline \multirow{3}{*}{ CASE 4} & ND & ND & ND & ND & ND & T1-T4 only & Pool fire(s) & $6.81 \times 10^{-4}$ \\
\hline & ND & ND & ND & ND & ND & T5-T8 only & Pool fire(s) & $5.16 \times 10^{-4}$ \\
\hline & ND & ND & ND & ND & ND & S1 & Pool fire & $3.21 \times 10^{-4}$ \\
\hline
\end{tabular}




\section{FIGURES}

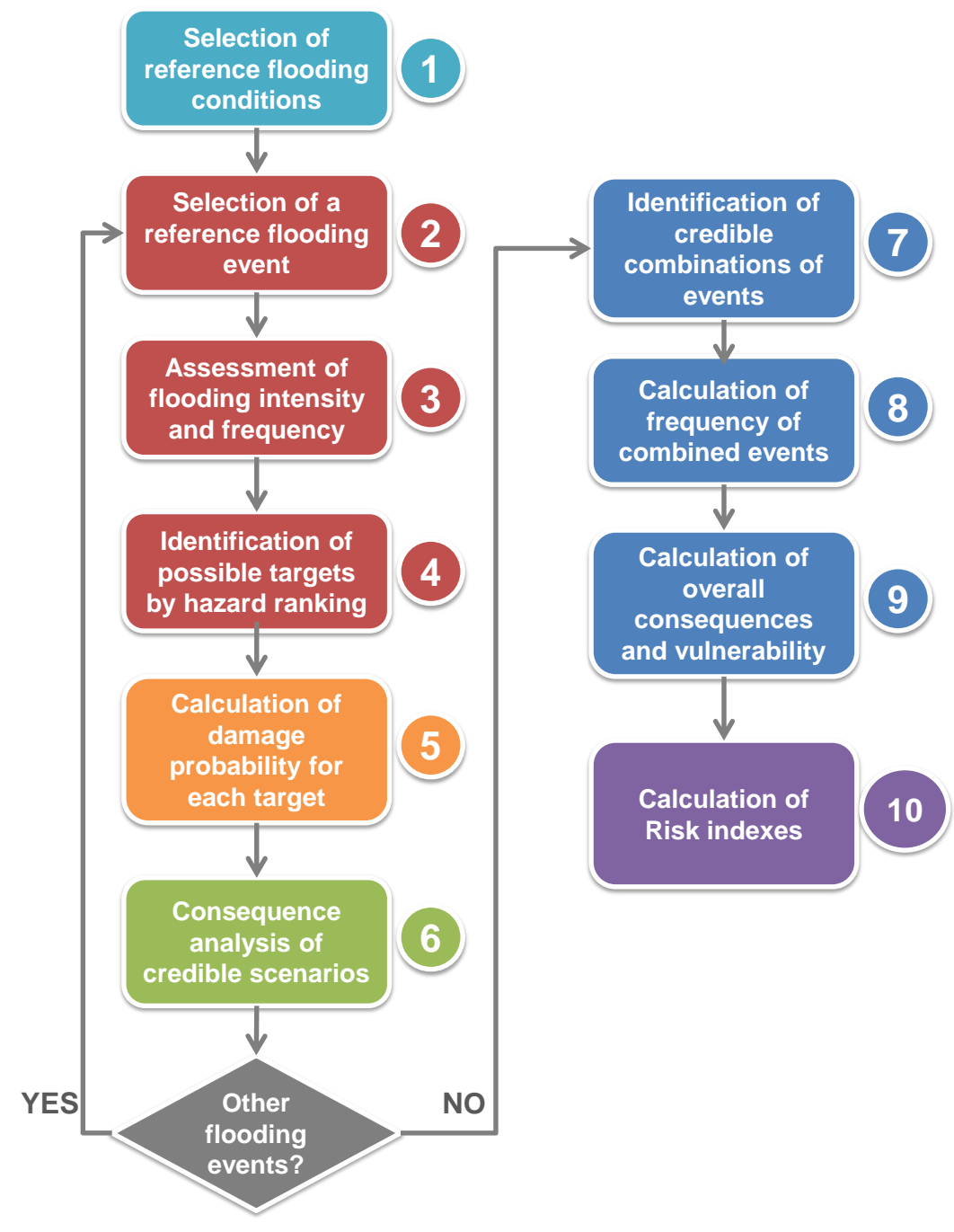

Figure 1: Methodology for the quantitative risk assessment of NaTech scenarios. 

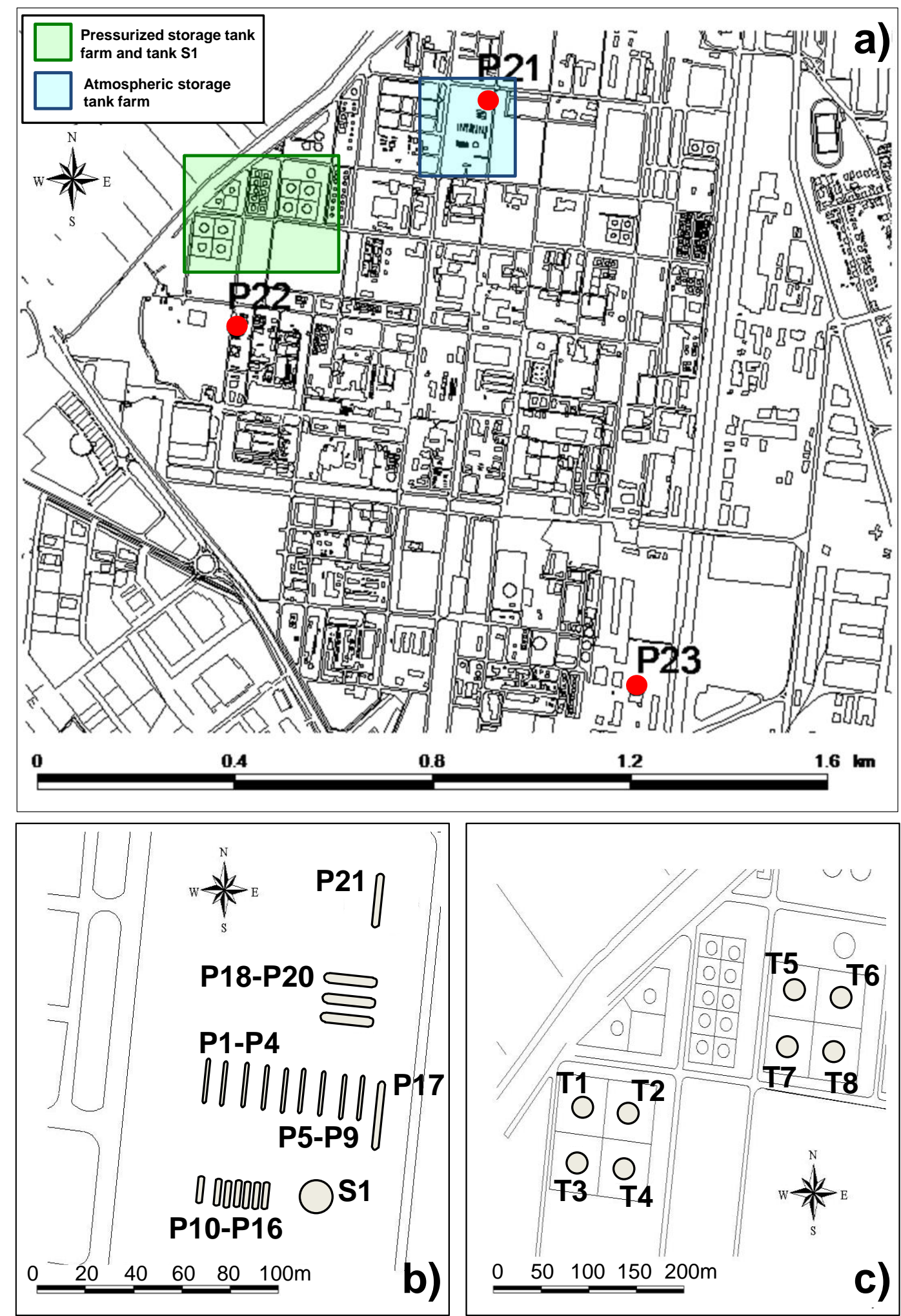

Figure 2: Layout considered for the case study: a) overview of the industrial area, position of the tank farms and location of pressurized tanks P21-P23; b) pressurized tank farm and storage tank S1; c) atmospheric tank farm. 


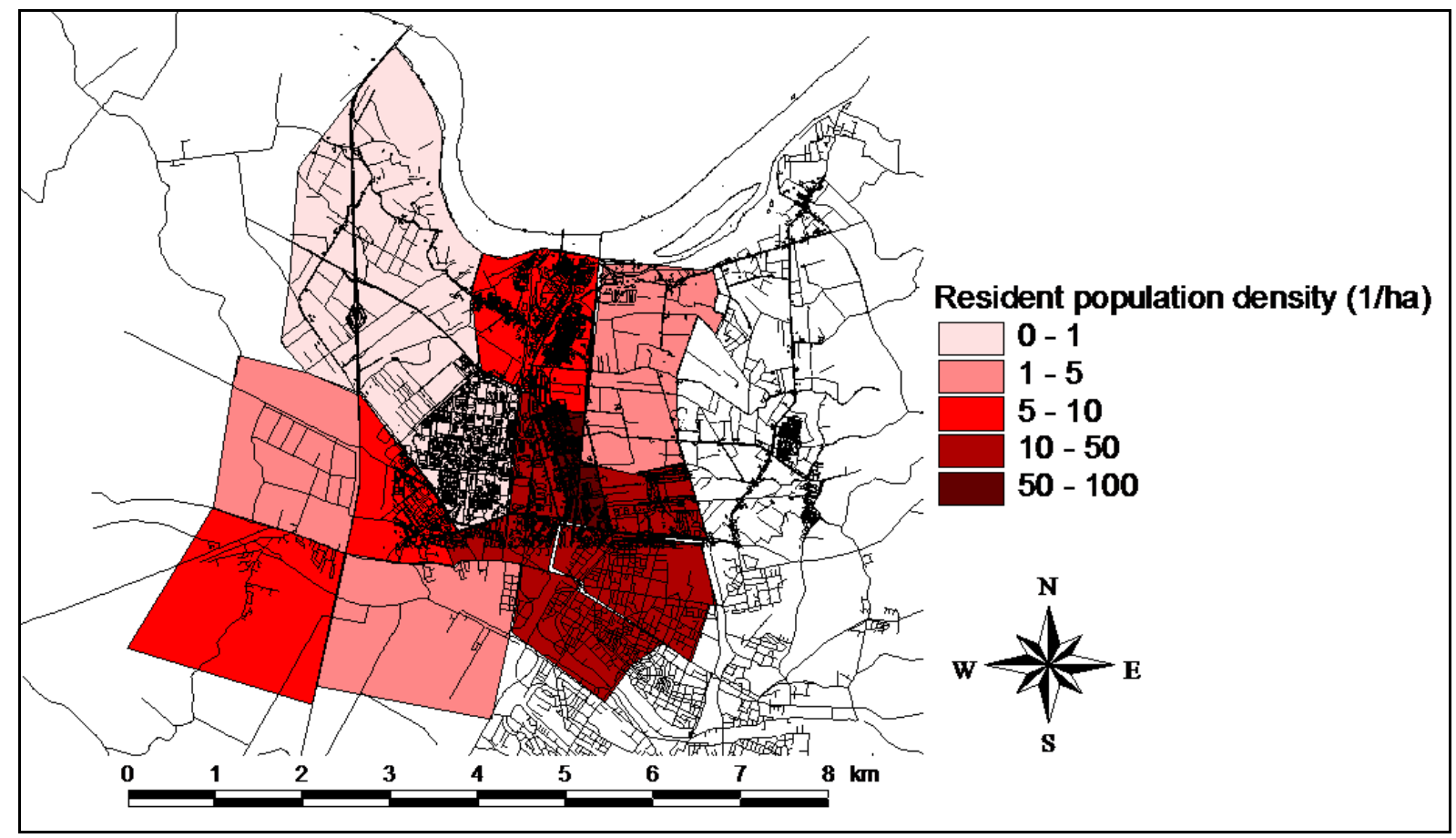

Figure 3: Density of the resident population surrounding the industrial area.

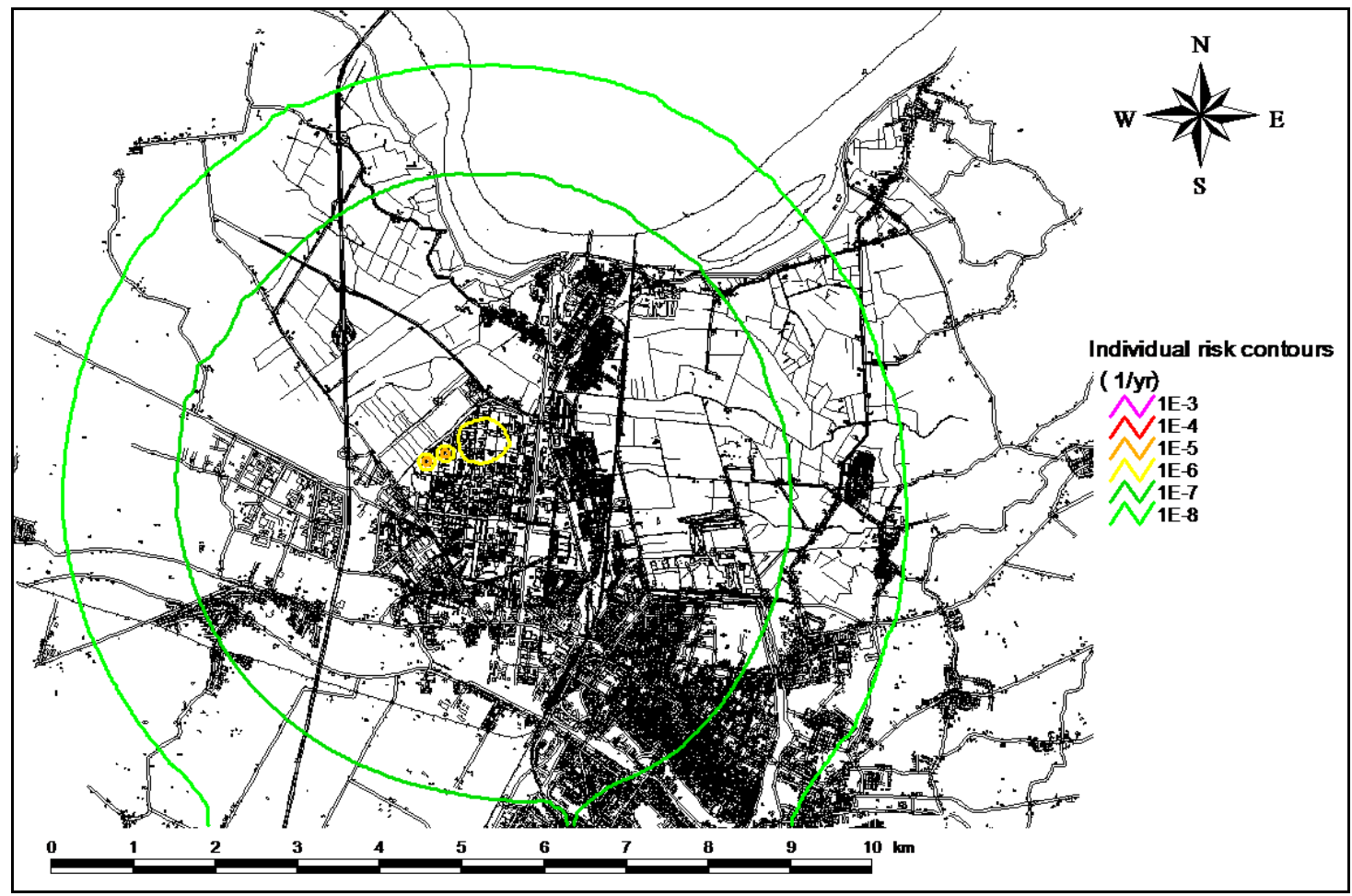

Figure 4: Individual risk contours (1/y) calculated for accident scenarios deriving from conventional release events due to internal failures. 


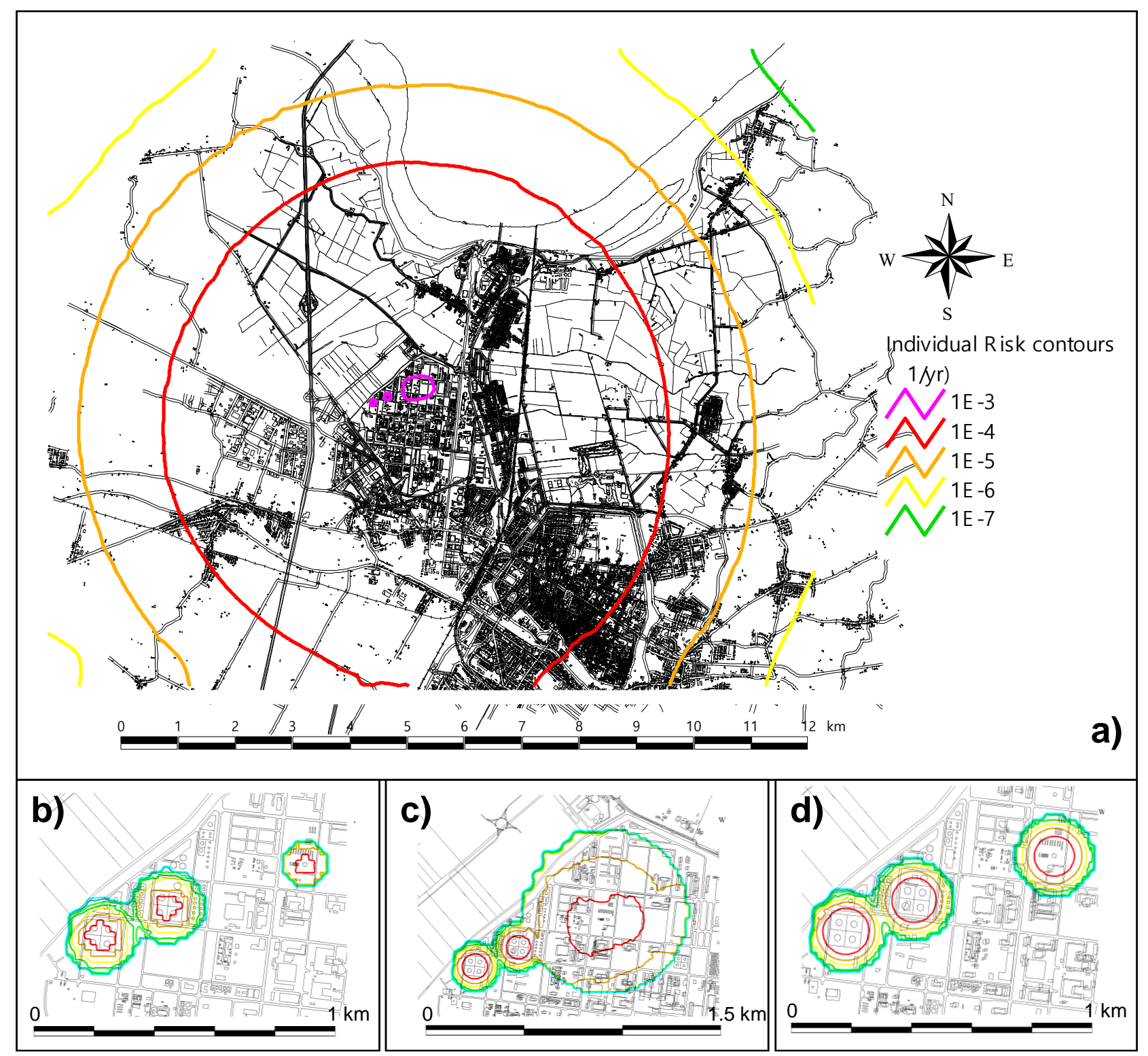

Figure 5: Individual risk contours (1/y) due to flood-triggered accidents: a) Case 1, b) Case 2, c) Case 3, d) Case 4. 


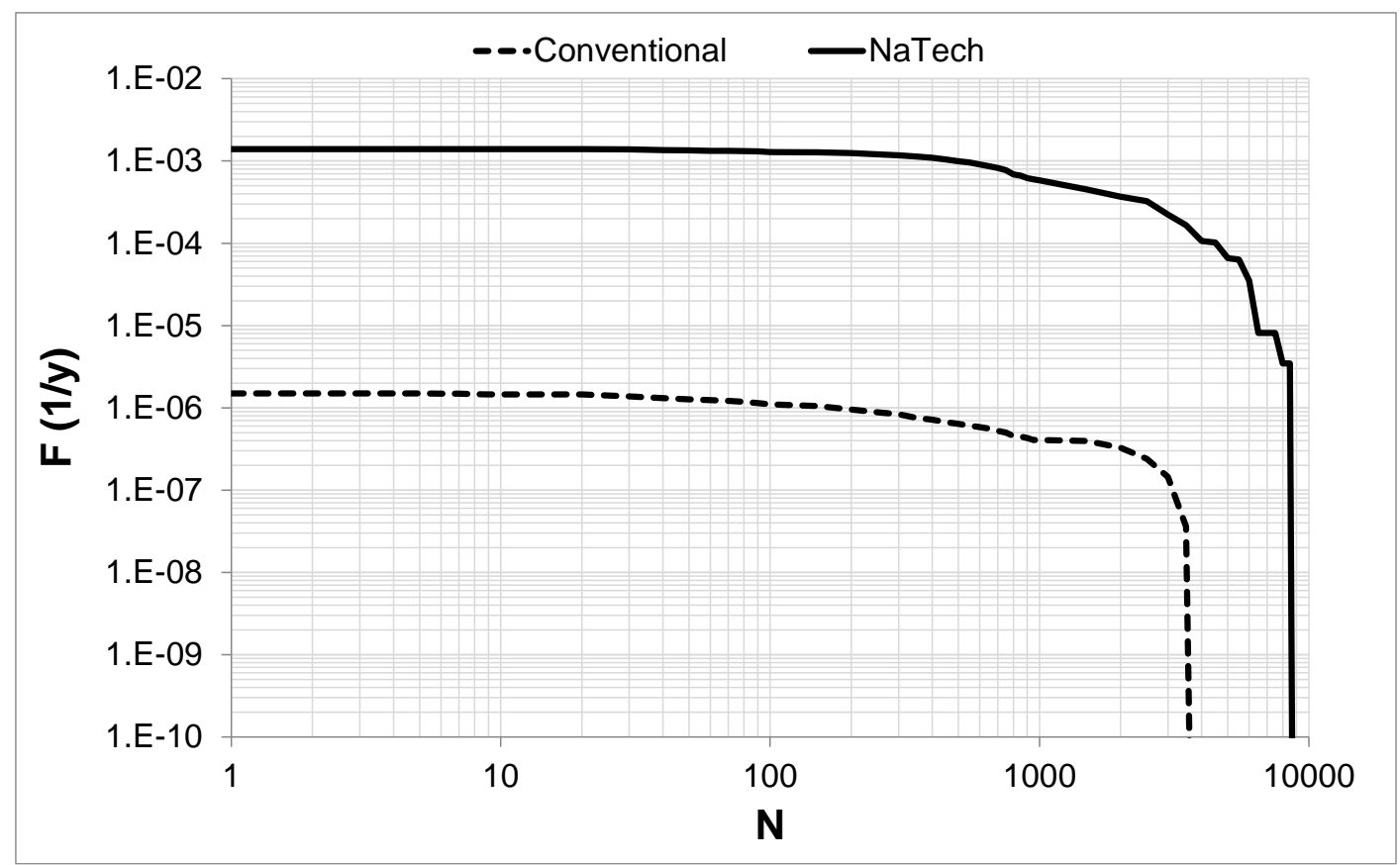

Figure 6: Societal risk $\mathrm{F} / \mathrm{N}$ curves evaluated for the conventional scenarios due to internal failures and for Case 1 reference flood scenario (NaTech). 